\title{
Defining the atherogenicity of large and small lipoproteins containing apolipoprotein B100
}

\author{
Murielle M. Véniant, ${ }^{1,2}$ Meghan A. Sullivan, ${ }^{1}$ Sun K. Kim, ${ }^{1}$ Patricia Ambroziak, ${ }^{1}$ \\ Alice Chu, ${ }^{3}$ Martha D. Wilson, ${ }^{4}$ Marc K. Hellerstein, $, 3,5,6$ Lawrence L. Rudel, ${ }^{4}$ \\ Rosemary L. Walzem, ${ }^{7}$ and Stephen G. Young ${ }^{1,2,5,6}$ \\ ${ }^{1}$ Gladstone Institute of Cardiovascular Disease, \\ ${ }^{2}$ Cardiovascular Research Institute, University of California, San Francisco, California, USA \\ ${ }^{3}$ Department of Nutritional Sciences, University of California, Berkeley, California, USA \\ ${ }^{4}$ Department of Pathology, Wake Forest University School of Medicine, Winston-Salem, North Carolina, USA \\ ${ }^{5}$ Department of Medicine, University of California, San Francisco, California, USA \\ ${ }^{6}$ The Medical Service, San Francisco General Hospital, San Francisco, California, USA \\ ${ }^{7}$ Kleberg Animal and Food Science Center, Texas A\&M University, College Station, Texas, USA
}

Address correspondence to: Murielle M. Véniant, Gladstone Institute of Cardiovascular Disease, PO Box 419100, San Francisco, California 94141-9100, USA. Phone: (415) 826-7500; Fax: (415) 285-5632; E-mail: mveniant@amgen.com.

Received for publication July 5, 2000, and accepted in revised form November 6, 2000.

Apo-E-deficient apo-B100-only mice (Apoe $\left.{ }^{-/} A_{p o b}{ }^{100 / 100}\right)$ and LDL receptor-deficient apo-B100-only mice $\left(\mathrm{Ldlr}^{-/}\right.$Apob $\left.{ }^{100 / 100}\right)$ have similar total plasma cholesterol levels, but nearly all of the plasma cholesterol in the former animals is packaged in VLDL particles, whereas, in the latter, plasma cholesterol is found in smaller LDL particles. We compared the apo-B100-containing lipoprotein populations in these mice to determine their relation to susceptibility to atherosclerosis. The median size of the apo-

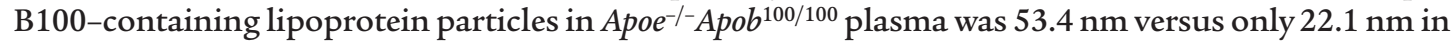
$L d l r^{-}-A p o b^{100 / 100}$ plasma. The plasma levels of apo-B100 were three- to fourfold higher in

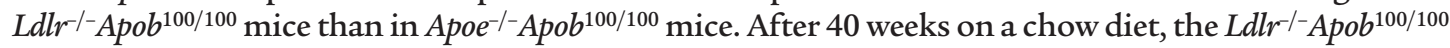
mice had more extensive atherosclerotic lesions than Apoe ${ }^{-/} A p o b^{100 / 100}$ mice. The aortic DNA synthesis rate and the aortic free and esterified cholesterol contents were also higher in the $L d l r^{-}-A p o b^{100 / 100}$ mice. These findings challenge the notion that all non-HDL lipoproteins are equally atherogenic and suggest that at a given cholesterol level, large numbers of small apo-B100-containing lipoproteins are more atherogenic than lower numbers of large apo-B100-containing lipoproteins.

J. Clin. Invest. 106:1501-1510 (2000).

\section{Introduction}

The recognition of hypercholesterolemia as a risk factor for atherosclerosis, and the identification of different classes of cholesterol-carrying lipoproteins, have spurred efforts to identify the most atherogenic lipoproteins. Over the past 40 years, clinical, epidemiological, genetic, and experimental animal studies have demonstrated that the apo-B-containing lipoproteins promote atherogenesis (1). However, the apo-B-containing lipoproteins are heterogeneous both in size and composition, and there has been controversy regarding which class of these lipoproteins is most atherogenic $(2,3)$. Much of this discussion has focused on whether particle size affects the intrinsic capacity of lipoproteins to promote atherogenesis. LDLs, which are at the small end of the size spectrum, are clearly atherogenic. LDLs are the principal cholesterol-carrying lipoproteins in the plasma of most human patients with coronary disease (1), and elevated LDL levels in familial hypercholesterolemia (FH) cause severe atherosclerosis (4). On the other hand, ample evidence indicates that larger particles (i.e., chylomicron and VLDL remnants) can be atherogenic. Cholesterolrich remnant lipoproteins accumulate in type III hyperlipoproteinemia, and affected individuals are at risk for atherosclerosis (5). In addition, population studies have uncovered links between elevated plasma levels of cholesterol-rich remnant particles and increased risk of coronary heart disease (6).

Studies in humans support the notion that both remnants and small LDL are atherogenic. However, these studies have not provided a clear answer to the question of whether different-sized lipoproteins differ in their intrinsic capacities to promote atherosclerosis. Thus, at a given total plasma cholesterol level, it is still not clear whether it matters - from the standpoint of atherogenesis - whether the cholesterol is carried in LDLs or in the larger remnant lipoproteins. This is a difficult issue to address with human studies. Many coronary disease patients have high levels of both remnants and LDL as well as other risk factors (e.g., diabetes mellitus, obesity, low HDL levels), making it difficult to sort out the importance of lipoprotein size. Studies of human genetic diseases have also failed to settle the issue of the intrinsic atherogenicities of large and small lipoproteins. Even if one assembled large groups of subjects with type III hyperlipoproteinemia and FH that were perfectly matched for total plasma cholesterol levels and other risk factors, defining the prevalence of athero- 
sclerosis still might not address the lipoprotein size issue definitively, given that the hyperlipidemia is lifelong in FH but generally starts only after young adulthood in type III hyperlipoproteinemia.

Animal models have also provided evidence for the atherogenicity of both remnants and LDL (7-10). Cholesterol-rich remnant lipoproteins accumulate in the plasma of chow-fed apo-E-deficient $\left(\right.$ Apoe $\left.^{-/-}\right)$mice, and those mice develop impressive atherosclerotic lesions (7, 8, 11-13). LDL receptor-deficient $(\mathrm{Ldlr} /-)$ mice have moderately increased LDL levels and a modestly increased susceptibility to atherosclerosis $(10,14,15)$. Unfortunately, Apoe $\mathrm{e}^{-/-}$and $\mathrm{Ldlr} / \mathrm{r}^{--}$mice have very different total plasma cholesterol levels $(\sim 450 \mathrm{mg} / \mathrm{dl}$ in Apoe ${ }^{-/-}$mice versus only $\sim 200 \mathrm{mg} / \mathrm{dl}$ in $\mathrm{Ldlr}^{-/-}$mice), making it nearly impossible to draw firm conclusions regarding the intrinsic atherogenicities of the lipoproteins in the two models. Another confounding factor is the overlapping size ranges of lipoproteins in the two models. In addition to accumulating VLDL and chylomicron remnants, Apoe $e^{-/-}$mice accumulate significant numbers of LDL-sized particles, and the extent to which these LDL particles contribute to susceptibility to atherosclerosis is not clear (16). A final difficulty in comparing $A p o e^{-/-}$and $\mathrm{Ldlr}^{-/}$mice relates to the apolipoprotein content of lipoproteins in the two models. The vast majority of the lipoproteins in Apoe-/- mice contain apo-B48, whereas the main protein constituent of LDL in $\mathrm{Ldlr}^{-/}$mice is apo-B100 $(16,17)$.

We have used gene targeting to produce mice that synthesize exclusively apo-B100 (apo-B100-only, or $A p o b^{100 / 100}$ mice), and have bred both apo-E-deficient apo-B100-only mice (Apoe $\left.e^{-/} A p o b^{100 / 100}\right)$ and LDL receptor-deficient apo-B100-only mice ( $L d l r^{-/-} A p o b^{100 / 100}$ ) $(16,18,19)$. The latter models provide an ideal opportunity for gaining insights into the atherogenicities of different lipoprotein classes. The spectrum of lipoprotein sizes in $A p o e^{-/-} A p o b^{100 / 100}$ and Ldlr-/-Apob ${ }^{100 / 100}$ mice is distinct - a nearly pure accumulation of LDL in Ldlr--Apob ${ }^{100 / 100}$ mice and a nearly pure accumulation of chylomicron and VLDL remnants in Apoe ${ }^{-/}$Apob ${ }^{100 / 100}$ mice. Moreover, the total plasma cholesterol levels in Apoe $e^{-/-} A p o b^{100 / 100}$ and $L d l r^{-/-} A p o b^{100 / 100}$ mice are virtually identical. Finally, the principal protein of the lipoproteins, apo-B100, is obviously the same in both models.

In this study, we characterized the lipoproteins and susceptibility to atherosclerosis in $A p o e^{-/-}$Apob ${ }^{100 / 100}$ and $L d l r^{-/} A p o b^{100 / 100}$ mice. Our experiments provide fresh insights into the intrinsic capacities of differentsized lipoproteins to promote atherosclerosis.

\section{Methods}

Production of apo-E-deficient mice and $L D L$ receptor-deficient mice that synthesize exclusively apo-B100. Apob ${ }^{100 / 100}$ mice were produced by mutating Apob codon 2153 (18). These $A p o b^{100 / 100}$ mice, which had a mixed genetic background ( $\sim 50 \%$ C57BL/6 and $~ 50 \% 129 / \mathrm{SvJae})$, were bred with C57BL/6 Apoe ${ }^{-/-}$mice (7) and C57BL/6 Ldlr-/- mice
(14) to produce multiple breeding pairs of Apoe ${ }^{-/-} A p o b^{100 / 100}$ and Ldlr ${ }^{-/} A p o b^{100 / 100}$ mice. While breeding Apoe ${ }^{-/-} A p o b^{100 / 100}$ and $L d l r^{-/-} A p o b^{100 / 100}$ mice, we also identified (from within littermates) multiple breeding pairs of two groups of control mice: apoE-deficient mice homozygous for the wild-type Apob allele $\left(A p o e^{-/-} A \mathrm{pob}^{+/+}\right)$and LDL receptor-deficient mice homozygous for the wild-type Apob allele $\left(\mathrm{Ldlr} /-A p o b^{+/+}\right)$. Each of the four groups of mice had similar genetic backgrounds ( $75 \%$ C $57 \mathrm{BL} / 6$ and $\sim 25 \%$ $129 /$ SvJae). The mice were weaned at 21 days of age and fed a chow diet containing $4.5 \%$ fat (Ralston Purina, St. Louis, Missouri, USA). Only female mice were included in this study ( $n=40$ mice each group). Each mouse was weighed and sacrificed at 280 days (40 weeks) of age.

Approximately one half of the mice were treated with ${ }^{2} \mathrm{H}_{2} \mathrm{O}$ for 3 weeks before they were sacrificed. On the first day of treatment, the mice received two intraperitoneal injections of $99.9 \%{ }^{2} \mathrm{H}_{2} \mathrm{O}$ (Isotech, Miamisburg, Ohio, USA) containing $0.9 \% \mathrm{NaCl}$ (volume of each injection [in $\mathrm{ml}$ ] equal to $2 \%$ of the body weight [in $\mathrm{g}]$ ). For the ensuing 3 weeks, their drinking water contained $5 \%{ }^{2} \mathrm{H}_{2} \mathrm{O}$.

Lipid measurements and lipoprotein analyses. Female mice were fasted for 4 hours before blood sampling. Total plasma cholesterol and triglyceride concentrations were measured on fresh plasma every 8 weeks with a colorimetric assay (Spectrum Cholesterol Assay; Abbott Laboratories, Irving, Texas, USA; and GB Triglyceride Kit; Boehringer Mannheim Biomedicals, Indianapolis, Indiana, USA) $(20,21)$. The fatty acid content of plasma cholesterol esters as well as the hepatic triglyceride, free cholesterol, and cholesterol ester contents were assessed by gas chromatography ( $n=8$ in each group) (22). The distribution of lipids within the plasma lipoproteins was determined by fractionating mouse plasma $(250 \mu \mathrm{l}$ pooled from 12 mice) by FPLC on a Superose 6 10/30 column $(20,21)$. In the case of the Ldlr/-Apob100/100 and $A p o e^{-/} A p o b^{100 / 100}$ mice, the VLDL, LDL, and HDL peaks from the FPLC experiments were collected and analyzed for their chemical composition (percentages of free cholesterol, esterified cholesterol, triglyceride, phospholipid, and protein) (22). The apolipoprotein content of the VLDL-IDL $(d<1.020 \mathrm{~g} / \mathrm{ml}), \operatorname{LDL}(d=1.020-1.050 \mathrm{~g} / \mathrm{ml})$, and HDL $(d=1.063-1.21 \mathrm{~g} / \mathrm{ml})$ from $L_{d l r^{-}-} A p o b^{100 / 100}$ and $A p o e^{-/-} A p o b^{100 / 100}$ mice was assessed on Coomassie blue-stained 4-20\% polyacrylamide/SDS gels.

Mouse apo-B100 concentrations. Apo-B100 levels in the plasma of 16- and 32-week-old Apoe-/-Apob ${ }^{100 / 100}$ and $L d l r^{--} A p o b^{100 / 100}$ mice were measured with a mAb-based competitive RIA (23).

Analysis of plasma lipoprotein size. For each plasma sample ( $n=15$ in each group), the $d<1.052 \mathrm{~g} / \mathrm{ml}$ fraction was prepared by ultracentrifugation. This fraction contains virtually all of the apo-B100 in the plasma (24). Lipoprotein particle diameters were determined by dynamic light scattering analysis with a Microtrac Series 150 Ultrafine particle analyzer fitted with a flexible conduit-sheathed probe tip (UPA-150; Microtrac, 
Clearwater, Florida, USA) (25). Raw particle-size distributions were converted to population percentiles, which were used to calculate the median particle diameter for each decile of lipoprotein size distribution.

Analysis of atherosclerotic lesions by morphometry. All mice were sacrificed at 280 days of age. Atherosclerosis was quantified in pinned-out aortas (26). Briefly, mice ( $n=40$ in each group) were perfused with PBS followed by a fixative solution (4\% paraformaldehyde, 5\% sucrose, $20 \mathrm{mM}$ EDTA [pH 7.4]). With the major branching vessels attached, the aorta was opened longitudinally from the iliac arteries to the aortic root. Then, all branching vessels were removed, including the great vessels in the neck, and most of the aorta (from the iliac bifurcation to a point equidistant between the aortic valve and the bracheocephalic artery) was removed and pinned out flat on a black wax surface. Images of the pinned-out aortas were recorded with a Polaroid digital microscope camera (Polaroid Corp., Cambridge, Massachusetts, USA). Each image was analyzed with Adobe Photoshop 5.5 (Adobe Systems, San Jose, California, USA) with gray and white thresholding to define lesions. Lesions were quantified by a trained observer blinded to mouse genotype. Data are reported as the percent of the aortic surface covered by lesions. The total length of the aorta was also measured, making it possible to measure the extent of atherosclerosis in different segments of the aorta.

Measurements of cholesterol and cholesterol ester content and DNA synthesis in the aorta. After morphometric quantification of lesions, each aorta was weighed and then snapfrozen in liquid $\mathrm{N}_{2}$. The frozen aortas were ground up with a mortar and pestle that had been precooled with liquid $\mathrm{N}_{2}$. The resulting aortic powder was suspended in $200 \mu \mathrm{l}$ of PBS; this suspension was used for the cholesterol measurements. In some cases, however, only one fourth of the volume was used for cholesterol measurements, and the remainder was used for measurements of aortic DNA synthesis. Each sample taken for cholesterol measurement was lyophilized, and lipids were extracted in $3 \mathrm{ml}$ of chloroform/methanol (2/1, vol/vol) containing $5 \alpha$-cholestane as an internal standard (22). Total lipid extracts were dried under nitrogen at $60^{\circ} \mathrm{C}$ and dissolved in hexane. Free and total cholesterol contents were determined with a DB17 $(15 \mathrm{~m} \times 0.53 \mathrm{~mm}$ ID, $1 \mu \mathrm{m}$ coating thickness; J \& W Scientific, Folsom, California, USA) gas-liquid chromatography column (two injections per sample) installed in a HewlettPackard 5890 gas chromatograph at $250^{\circ} \mathrm{C}$ (Palo Alto, California, USA). Cholesterol ester content was calculated as the difference between free and total cholesterol as measured before and after saponification and reextraction of the nonsaponifiable sterol into hexane. The protein content of the delipidated aortic tissue was determined with a Lowry protein assay (27).

Aortic DNA synthesis was measured by providing 5\% ${ }^{2} \mathrm{H}_{2} \mathrm{O}$ in drinking water for 3 weeks before sacrifice. Deuterium incorporated into the deoxyribose $(\mathrm{dR})$ of newly synthesized DNA was quantified by mass spec- trometry (28-32). DNA was extracted from aorta and femoral bone marrow with the DNeasy Tissue Kit (QIAGEN, Valencia, California, USA). Enzymatic hydrolysis to deoxyribonucleosides was performed by incubation with nuclease P1, snake venom phosphodiesterase, and DNase, followed by alkaline phosphatase (28). Deoxyadenosine was isolated with a Supelco column and converted to $\mathrm{dR}$-aldonitrile-triacetate by heating in $1 \%$ hydroxylamine:pyridine followed by addition of acetic anhydride. The samples were then dried under $\mathrm{N}_{2}$ and reconstituted in ethyl acetate for analysis by gas chromatography/mass spectrometry (29). The ions at 198,199 , and $200 \mathrm{~m} / z$ were monitored under the selected ion recording mode. Aortic DNA synthesis is expressed relative to the incorporation in cells isolated from bone marrow in the same animal. Bone marrow DNA is essentially fully replaced within 7-10 days in the mouse and thereby serves as an internal standard in each animal (32). Deuterium incorporation into $d R$ in DNA can be measured from either $\left[{ }^{2} \mathrm{H}\right]$ glucose or ${ }^{2} \mathrm{H}_{2} \mathrm{O}$, with the same results (32). In this study, ${ }^{2} \mathrm{H}_{2} \mathrm{O}$ was used because it can be maintained at a constant enrichment in an animal for a long-term labeling study.

Power calculations and statistical analysis. The decision to include at least 40 mice in each group was based on power calculations (SigmaStat 2.03; Jandel Scientific, San Rafael, California, USA) with data from an earlier mouse atherosclerosis study (16). These calculations revealed that group sizes equal to or greater than 35 were necessary to detect a $35 \%$ difference in lesions at a power of 0.8 and a confidence level of $95 \%$.

Mean lipid levels are reported with the SEM. Differences in triglyceride levels, cholesterol levels, and weights were modeled by repeated-measures ANOVA with time being an intragroup factor and genotype an intergroup factor. The extent of atherosclerotic lesions is reported as the mean \pm SEM for each group. Differences were assessed by ANOVA. Relationships between lipid levels and atherosclerotic lesions were assessed by univariate analysis with StatView (SAS Institute, Cary, North Carolina, USA).

\section{Results}

Plasma lipid and lipoprotein levels. Apoe-/-Apob $100 / 100$ and Ldlr/-Apob ${ }^{100 / 100}$ mice had similar total cholesterol levels (Figure 1, top), and at the conclusion of the study, their cholesterol levels were not statistically different $(P=0.85)$. At 8 weeks, the total cholesterol levels were somewhat higher in the Apoe $e^{-/-} A p o b^{100 / 100}$ mice than in the $\mathrm{Ldlr}^{-/} A p o b^{100 / 100}$ mice, but at 16, 24, and 32 weeks, the reverse was true. As expected, the total cholesterol levels were higher in $A p o e^{-/-} A p o b^{+/+}$mice than in the other groups of mice, whereas they were lower in $\mathrm{Ldlr}^{-/-} \mathrm{Apob} \mathrm{b}^{+/+}$ mice (Figure 1, top). Size-fractionation of the plasma by FPLC revealed high levels of VLDL cholesterol in both Apoe e $^{-/}$Apob ${ }^{100 / 100}$ and Apoe $e^{-/-}$Apob $^{+/+}$mice. However, IDL/LDL-cholesterol levels were far lower in Apoe ${ }^{-/-}$Apob ${ }^{100 / 100}$ mice than in Apoe ${ }^{-/-}$Apob ${ }^{+/+}$mice (Figure 1 , middle). Both groups of LDL receptor-deficient 
mice had elevated LDL cholesterol levels, but they were higher in $\mathrm{Ldlr}^{-/} \mathrm{Apob}^{100 / 100}$ mice than in $\mathrm{Ldlr}^{-/} \mathrm{Apob}^{+/+}$ mice. Neither group of LDL receptor-deficient mice had significant amounts of VLDL cholesterol. HDL cholesterol levels were identical in $A p o e^{-/-} A p o b^{100 / 100}$, $\mathrm{Apoe}^{-/-} \mathrm{Apob}^{+/+}$, and Ldlr- Apob ${ }^{100 / 100}$ mice, but were high-
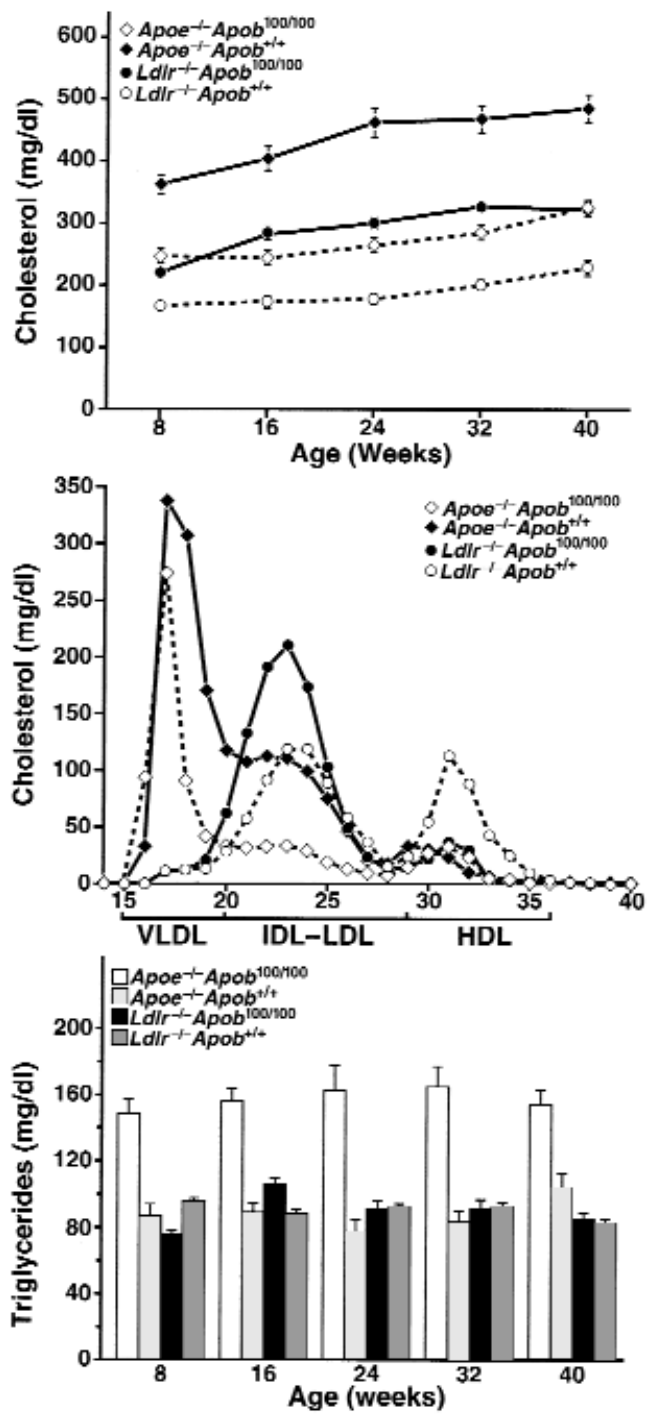

Figure 1

Lipid and lipoprotein levels in Apoe $^{-/-}$Apob $^{100 / 100}(n=44)$, Apoe $^{-/-}$Apob $^{+/+}$ $(n=40), L_{d l} r^{-}-\operatorname{Apob}^{100 / 100}(n=42)$, and $\mathrm{LdIr}^{-/} \mathrm{Apob}^{+/+}(n=40)$ mice. The top panel shows the mean plasma cholesterol levels at 8, 16, 24, 32, and 40 weeks of age; error bars represent SEM. When all five cholesterol values from the different time points were averaged, the total cholesterol level was somewhat higher in $L d l r^{-1-} A p o b^{100 / 100}$ than in $A p o e^{-/}-A p o b^{100 / 100}$ mice $(298 \pm 5$ versus $280 \pm 7 \mathrm{mg} / \mathrm{dl} ; P<0.05)$. The cholesterol levels in $L d l r^{-1} A p o b^{100 / 100}$ and $A p o e^{-/-} A p o b^{100 / 100}$ mice were significantly different from those in the two control groups $(P<0.0001)$. The middle panel shows the distribution of cholesterol within the lipoprotein fractions. The bottom panel shows the plasma triglyceride levels. Mean triglyceride levels (from all measurements) were significantly higher in the $A p o e^{-/-} A p o b^{100 / 100}$ mice $(150 \pm 5 \mathrm{mg} / \mathrm{dl})$ than in the other groups $\left(88 \pm 4 \mathrm{mg} / \mathrm{dl}\right.$ for Apoe $^{-/-} \mathrm{Apob}^{+/+}$mice, $89 \pm 2$ $\mathrm{mg} / \mathrm{dl}$ for $L d \mathrm{ll} \mathrm{r}^{\prime-A p o b}{ }^{100 / 100}$ mice, and $91 \pm 3 \mathrm{mg} / \mathrm{dl}$ for $L d l r^{\prime-A} A p o b^{+/+}$ mice; $P<0.0001$ for each comparison). er in $\mathrm{Ldlr}^{-/} \mathrm{Apob}^{+/+}$mice (Figure 1, middle). The triglyceride levels were higher in $A p o e^{-/-} A p o b^{100 / 100}$ mice than in the other groups (Figure 1, lower).

The fatty acid content of the plasma cholesterol esters was essentially identical in all four groups of mice, with the most abundant fatty acids being linoleate $(35 \%)$, oleate $(35 \%)$, and palmitate $(12 \%)$. There were no major differences in the triglyceride, free cholesterol, and cholesterol ester contents of the livers of the four groups of mice (data not shown).

Lipoprotein size and number. The apo-B-containing lipoproteins were substantially larger in Apoe-/-Apob $100 / 100$ mice than in Ldlr-/-Apob ${ }^{100 / 100}$ mice (Figure 2). The apo-B-containing lipoproteins were also large in $\mathrm{Apoe}^{-/-} \mathrm{Apob}^{+/+}$mice, although not as large as in $A p o e^{-/-} A p o b^{100 / 100}$ mice. Most of the lipoproteins

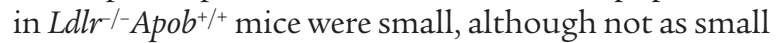
as in $\mathrm{Ldlr}^{-}{ }^{-} \mathrm{Apob} \mathrm{b}^{100 / 100}$ mice (Figure 2). There was little overlap in the spectrum of lipoprotein sizes in Apoe-/-Apob ${ }^{100 / 100}$ and Ldlr-/-Apob ${ }^{100 / 100}$ mice; $90 \%$ of particles in $L_{d l r^{-}-} A p o b^{100 / 100}$ were smaller (90th percentile, $33.8 \pm 0.6 \mathrm{~nm} ; n=21$ mice) than the smallest $10 \%$ of particles in Apoe - $^{-A p o b}{ }^{100 / 100}$ mice (10th percentile, $35.7 \pm 1.08 \mathrm{~nm} ; n=15$ mice).

Finding similar total plasma cholesterol levels in Ldlr- Apob ${ }^{100 / 100}$ and Apoe $e^{-/-A p o b}{ }^{100 / 100}$ mice, despite markedly different lipoprotein particle sizes, suggested that the number of particles in the plasma of these mice would differ substantially. Indeed, the plasma apo-B100 concentration (an index of the number of particles in the plasma) was three- to fourfold greater in $L d l r^{-}-A p o b^{100 / 100}$ mice than in Apoe $e^{-/} A p o b^{100 / 100}$ mice (Figure 3).

Analysis of lipoprotein composition. We measured the free cholesterol, phospholipid, cholesterol ester, triglyceride, and protein contents of the VLDL, LDL, and HDL of $\mathrm{Ldlr}^{-/} A p o b^{100 / 100}$ and Apoe ${ }^{-/-} A p o b^{100 / 100}$ mice, and then expressed the data as percentages of particle mass. A few significant differences were observed in the VLDL and LDL fractions. In the VLDL of female $A p o e^{-/} A p o b^{100 / 100}$ mice, the percentage of triglycerides was lower $(17 \%)$ and the percentage of cholesterol esters was higher (42\%), compared with the VLDL from Ldlr ${ }^{-}$Apob ${ }^{100 / 100}$ mice (32\% triglycerides and $27 \%$ cholesterol esters). The opposite trend was apparent when comparing the LDL fractions (a higher percentage of triglycerides and a lower percentage of cholesterol esters in $\left.A_{p o e^{-/}} \mathrm{Apob}^{100 / 100} \mathrm{LDL}\right)$. There were no significant differences in the chemical composition of the HDL from Ldlr-/-Apob ${ }^{100 / 100}$ and $A p o e^{-/-} A p o b^{100 / 100}$ mice.

The apolipoprotein contents of the lipoprotein fractions of $\mathrm{Ldlr}^{-/} A p o b^{100 / 100}$ and $A p o e^{-/} A p o b^{100 / 100}$ mice were compared by SDS-PAGE. Not surprisingly, differences were apparent. There were increased amounts of apo-AI and apo-AIV in the VLDL and LDL of Apoe- ${ }^{-}$Apob ${ }^{100 / 100}$ mice. Those differences were not surprising based on descriptions of the lipoproteins in apoE-deficient humans and mice $(8,12,33)$. The VLDL from Apoe $e^{-/} A p o b^{100 / 100}$ mice also contained more of the $\mathrm{C}$ apolipoproteins. Of course, none of the lipoproteins 


\section{Figure 2}

Lipoprotein sizes in the four different groups of mice. The median diameter of lipoproteins in Apoe $e^{-/-} A p o b^{100 / 100}$ mice $(n=15)$ was $140 \%$ larger than in $L d l r^{-}-A p o b^{100 / 100}(n=21)$ mice, 90\% larger than in Ldll I-Apob $^{+/+}$mice $(n=17)$, and 50\% larger than in Apoe - $^{-/} \mathrm{Apob}^{+/+}$ mice $(n=16)$. The size of VLDL $(d<1.006 \mathrm{~g} / \mathrm{ml})$ particles ranged from an average of $33.4 \mathrm{~nm}$ in $L d l r^{-1-A p o b} b^{100 / 100}$ mice to $61 \mathrm{~nm}$ in Apoe ${ }^{-/-}$Apob $b^{100 / 100}$ mice; the size of IDL $(d=1.006-1.020 \mathrm{~g} / \mathrm{ml})$ particles ranged from an average of $27 \mathrm{~nm}$ in $L d l / r^{-1} A p o b^{100 / 100}$ mice to 38 $\mathrm{nm}$ in Apoe $^{-/-}$Apob ${ }^{100 / 100}$ mice; the size of LDL $(d=1.020-1.052 \mathrm{~g} / \mathrm{ml})$ particles was $23 \mathrm{~nm}$ in $A p o e^{-/-A p o b^{100 / 100}}$ plasma, $20 \mathrm{~nm}$ in $\mathrm{Apoe}^{-/-} \mathrm{Apob}^{+/+}$plasma, $22 \mathrm{~nm}$ in Ldll r-Apob ${ }^{100 / 100}$ plasma, and $19 \mathrm{~nm}$ in $\mathrm{Ldll} \mathrm{r}^{-/-} \mathrm{Apob}^{+/+}$plasma. The difference in size between the bottom and top deciles of particles was $64.0 \mathrm{~nm}$ for $A p o e^{-/-} A p o b^{100 / 100}$ mice, $27.2 \mathrm{~nm}$ for $A p o e^{-/-} A p o b^{+/+}$mice, $17.8 \mathrm{~nm}$ for $L d l r^{/-} A p o b^{+/+}$mice, and $17.0 \mathrm{~nm}$ for $L d \mathrm{ll} \mathrm{r}^{-}$Apob ${ }^{100 / 100}$ mice.

from $A p o e^{-/} A p o b^{100 / 100}$ mice contained apo-E. The LDL from $L d l r^{-}-A p o b^{100 / 100}$ plasma did not contain apo-AI but did contain surprisingly large amounts of apo-E. For the HDL, the relative amounts of the major apolipoproteins, apo-AI and apo-AII, were similar in both groups of mice. However, there were some differences in the minor apolipoproteins. The HDL from Apoe $/-A p o b^{100 / 100}$ mice contained more apo-AIV and more of the $\mathrm{C}$ apolipoproteins. There was obviously more apo-E in the HDL of the Ldlr/-Apob $b^{100 / 100}$ mice.

Susceptibility to atherosclerosis. The Ldlr-/-Apob ${ }^{100 / 100}$ mice had far more atherosclerosis than the Apoe $/-A p o b^{100 / 100}$ mice at 40 weeks $(14.0 \pm 0.46 \%$ versus only $4.8 \pm 0.37 \%$ of the aortic surface; $P<0.0001$ ) (Figure 4, top). Despite much higher total plasma cholesterol levels, $\mathrm{Apoe}^{-/-} \mathrm{Apob}^{+/+}$mice had much less atherosclerosis than the $\mathrm{Ldlr}^{-/}$Apob ${ }^{100 / 100}$ mice $(7.47 \pm 0.67 \%$ versus $14.0 \pm 0.46 \% ; P<0.0001$ ) (Figure 4 , top). The $\mathrm{Ldlr}^{-1-} \mathrm{Apob}^{+/+}$mice had minimal atherosclerosis $(0.41 \pm$ $0.16 \%, \sim 3 \%$ of that in Ldlr ${ }^{-}-A p o b^{100 / 100}$ mice; $P<0.0001$ ), even though their total plasma cholesterol levels were only $105 \mathrm{mg} / \mathrm{dl}$ lower than in $\mathrm{Ldl} / \mathrm{r}^{-}$-Apob ${ }^{100 / 100}$ mice (Figure 4, top). The pattern of atherosclerosis susceptibility was similar for the top and middle thirds of the aorta (Figure 4, bottom). Representative pinned-out aortas are shown in Figure 5. The microscopic appearance of the lesions in the proximal aortas was similar in the different groups, although there were obvious differences in the extent of lesions (Figure 6).

\section{Figure 3}

Apo-B100 levels in Apoe-/-Apob ${ }^{100 / 100}(n=36)$ and Ldlr/-Apob ${ }^{100 / 100}$ mice $(n=34)$ at 16 and 32 weeks of age. Apo-B100 levels were not measured in the two control groups (Apoe ${ }^{-/-} \mathrm{Apob}^{+/+}$and $\mathrm{Ldlr^{-/ }} \mathrm{Apob}^{+/+}$) because the RIA is specific for apo-B100, and the plasma of those mice contains both apo-B100 and apo-B48. Previously, however, we showed that $\mathrm{Apoe}^{-/-} \mathrm{Apob}^{+/+}$mice have lower apo-B100 levels in their plasma than $A p o e^{-/-} A p o b^{100 / 100}$ mice, and that $L d l r^{1-} A p o b^{+/+}$mice have lower apo-B100 levels than LdIr/-Apob ${ }^{100 / 100}$ mice (50).

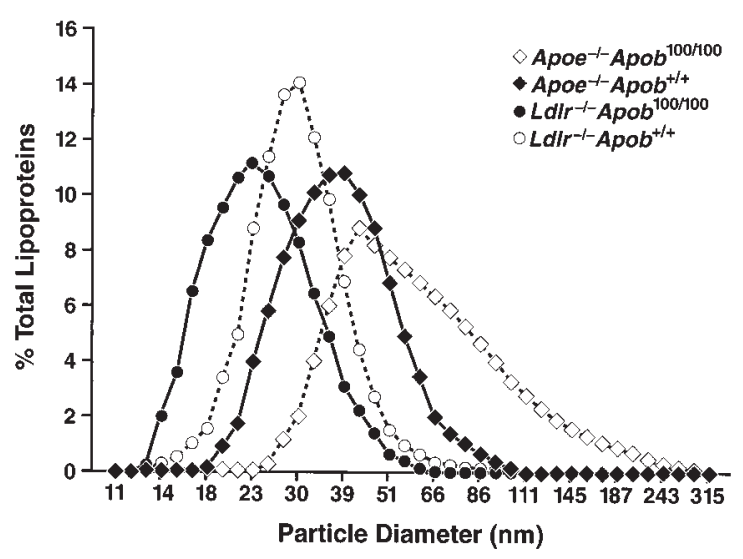

A plot of atherosclerotic lesion measurements and total cholesterol levels in $\mathrm{Ldll}^{-/} \mathrm{Apob} \mathrm{b}^{100 / 100}$ and Apoe ${ }^{-/}$Apob ${ }^{100 / 100}$ mice revealed that the Ldlr ${ }^{-}-A_{p o b} b^{100 / 100}$ mice had far more atherosclerosis than Apoe $e^{-/} A p o b^{100 / 100}$ mice at the same total cholesterol levels (Figure 7, top). A plot of atherosclerotic lesions versus plasma apo-B100 levels (Figure 7, bottom) revealed that the group with the highest apo-B100 levels ( Ldl/ /-Apob ${ }^{100 / 100}$ mice) had the most atherosclerosis.

We also measured the levels of free and esterified cholesterol in the aorta and the DNA synthesis rate in the aorta. Aortic free and esterified cholesterol levels were greater in $\mathrm{Ldll}^{-/}$-Apob ${ }^{100 / 100}$ than in Apoe-/-Apob ${ }^{100 / 100}$ mice $(P<0.0001)$ (Figure 8 , a and $b$ ), and the pattern for the four groups resembled that obtained with morphometric techniques (Figure 4). The correlation between the morphometric assessment of lesions and the content of free and esterified cholesterol was high when all mice were included in the analysis $(r=0.855$, $P<0.0001$ for free cholesterol; $r=0.857, P<0.0001$ for esterified cholesterol).

The aortic DNA synthesis rate was greater in $L d l r^{-/} A p o b^{100 / 100}$ mice than in Apoe ${ }^{-/-A p o b} b^{100 / 100}$ mice $(P<0.001)$ (Figure 8c). The degree of aortic DNA synthesis was high; as many as $10-12 \%$ of all of the cells in the aorta had divided during the 3 weeks of ${ }^{2} \mathrm{H}_{2} \mathrm{O}$ administration. The correlation between morphometric assessment of lesions and the aortic DNA synthesis rate was only moderate $(r=0.574, P<0.0001)$. The cor-

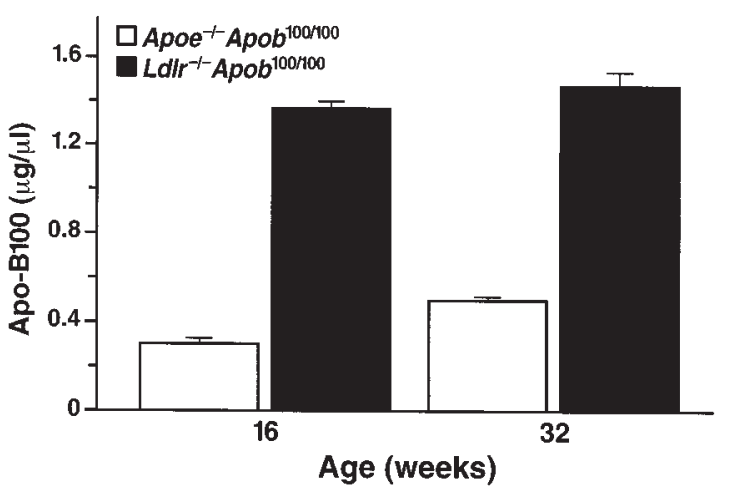




\section{Figure 4}

Morphometric assessment of atherosclerotic lesions in $A p o e^{-/-} A p o b^{100 / 100}$

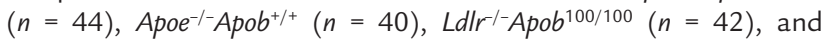
$\mathrm{Ldll}^{\prime-} \mathrm{Apob}^{+/+}(n=40)$ mice. The top panel shows the extent of atherosclerotic lesions in the entire aorta. Differences between all groups were significant at the $P<0.0001$ level with one exception: the lesions in $A p o e^{-/-} \mathrm{Apob}^{+/+}$mice were different from those in $\mathrm{Apoe}^{-/-} \mathrm{Apob}^{100 / 100}$ mice at $P=0.0004$. The bottom panel shows the extent of lesions in the top and middle third of the aorta. The top and middle thirds of the aortas contained greater than $90 \%$ of the total aortic lesions.

relation between cholesterol content in the aorta and the DNA synthesis rate was somewhat lower $(r=0.482$, $P<0.0001$ for free cholesterol; $r=0.469, P<0.0001$ for esterified cholesterol).

\section{Discussion}

In this study, we defined the susceptibility to atherosclerosis in Apoe-/-Apob ${ }^{100 / 100}$ and Ldlr- ${ }^{-/}$Apob ${ }^{100 / 100}$ mice - two hypercholesterolemic mouse models with distinct lipoprotein profiles. The total plasma cholesterol levels in the two mice were essentially identical. However, the vast majority of the cholesterol in the plasma of Apoe ${ }^{-/-} A p o b^{100 / 100}$ mice is in VLDL-sized particles, while nearly all of the cholesterol in $\mathrm{Ldll}^{-/}$-Apob ${ }^{100 / 100}$ mice is in LDL-sized particles. The finding of similar plasma cholesterol levels, despite striking differences in the sizes of cholesterol-carrying particles, was explained by differences in the numbers of lipoproteins in the plasma. The apo-B100 levels were three- to fourfold higher in Ldlr-/-Apob ${ }^{100 / 100}$ mice than in Apoe-/-Apob ${ }^{100 / 100}$ mice.

The two different mouse models provided an ideal opportunity to explore intrinsic differences in the atherogenicities of VLDL- and LDL-sized lipoproteins. More properly, perhaps one could state that the two models enabled us to compare the atherogenicity of two distinct phenotypes-large numbers of small LDL particles versus small numbers of large lipoproteins. The results were clear and unequivocal: the mice with larger numbers of small lipoproteins (i.e., Ldlr-/-Apob100/100 mice) had more atherosclerosis than mice with smaller numbers of large lipoproteins (i.e., Apoe $e^{-/}$Apob ${ }^{100 / 100}$ mice). Thus, our studies challenge the notion that all non-HDL lipoproteins are equally atherogenic.

Two control groups, Apoe $\mathrm{e}^{-/-} \mathrm{Apob}^{+/+}$mice and $\mathrm{Ldll}^{-/} \mathrm{Apob}^{+/+}$mice, were analyzed in our study, and results in both groups provided a reassuring measure of internal consistency. The $\mathrm{Ldlr}^{-} \mathrm{Apob}^{+/+}$mice maintained lower total cholesterol levels than $\mathrm{Ldlr}^{-/} \mathrm{A} A \mathrm{pob} \mathrm{b}^{100 / 100}$ mice and had less atherosclerosis, whereas $A p^{-/-} \mathrm{Apob}^{+/+}$mice had higher lipid levels than $A p o e^{-/-}$Apob ${ }^{100 / 100}$ mice and had more

\section{Figure 5}

Representative Sudan IV-stained thoracic aortas. The amount of atherosclerosis in these four aortas matched the mean level for each group.
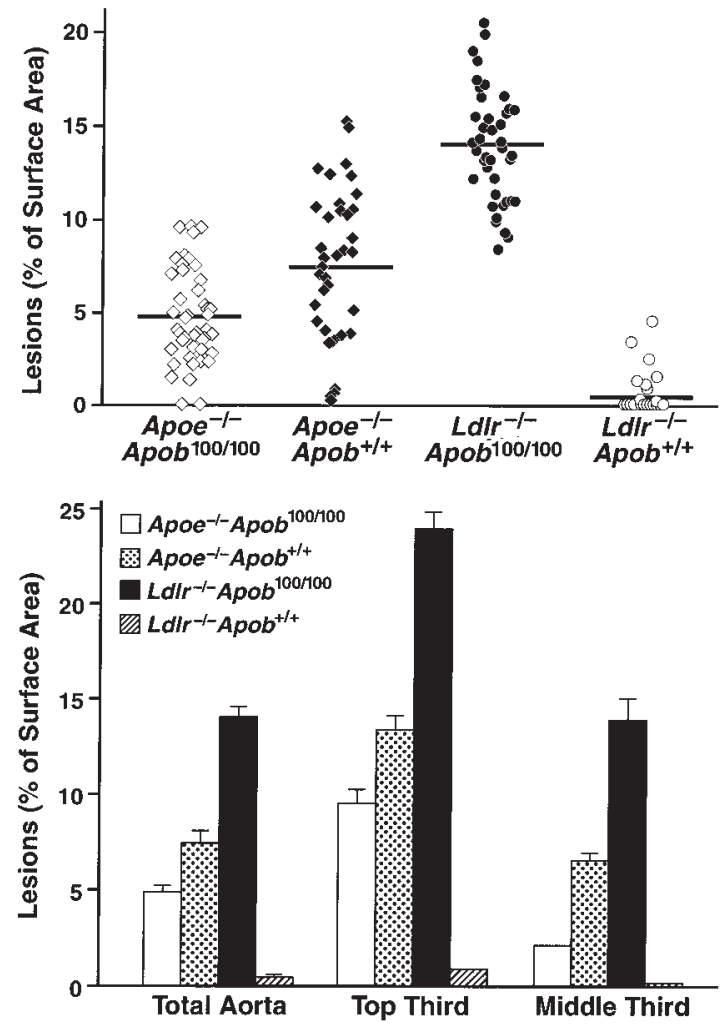

atherosclerosis.

The reduced amount of atherosclerosis in Apoe-/-Apob ${ }^{100 / 100}$ mice than in $\mathrm{Ldlr}^{-/}$-Apob ${ }^{100 / 100}$ mice suggests that the cholesterol in lipoproteins larger than LDL is less potent in promoting atherogenesis. Interestingly, most of the cholesterol in $\mathrm{Apoe}^{-/-} \mathrm{Apob}^{+/+}$mice is also carried in lipoproteins larger than LDL, and those mice had less atherosclerosis than Ldlr ${ }^{-}$Apob ${ }^{100 / 100}$ mice - even though they had far higher total cholesterol levels. Figure 9 shows the mean values for total plasma cholesterol levels and atherosclerotic lesions for each of the four groups of mice. Plotted in this fashion, the data naturally suggest the hypoth-
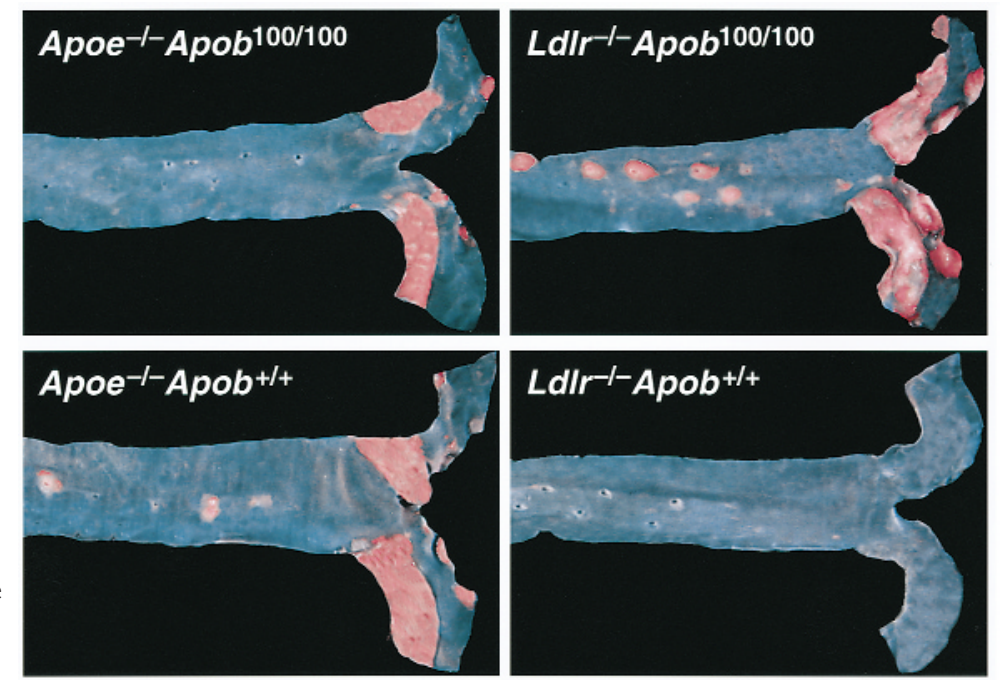


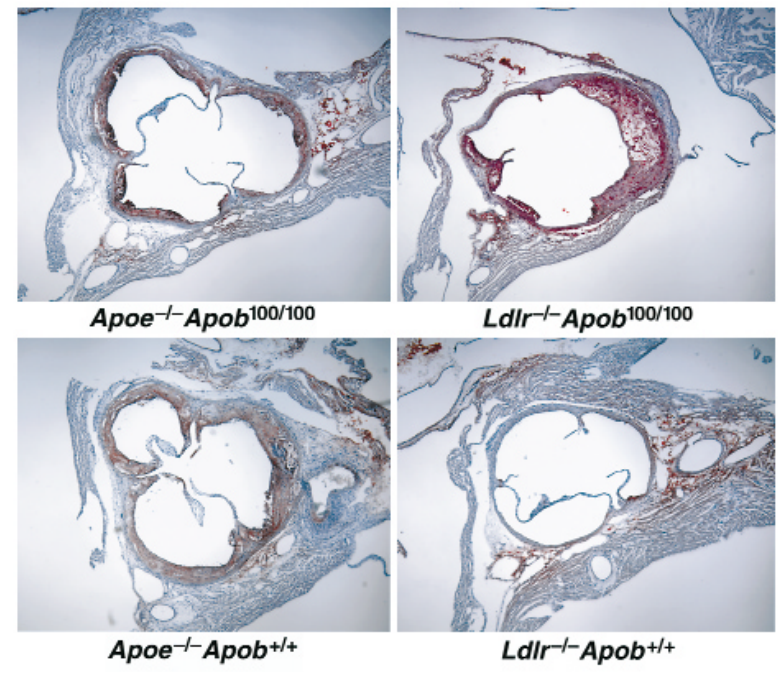

Figure 6

Oil Red O-stained sections of proximal aortic roots.

esis that lipoprotein size might substantially modify the degree of atherosclerosis in response to hypercholesterolemia. In other words, it appears that there could be distinct plasma cholesterol versus atherosclerosis relationships for different-sized lipoproteins. When most of the lipoproteins are in the LDL size range (as in the two groups of LDL receptor-deficient mice), increasing the plasma cholesterol levels from approximately 200 to approximately $300 \mathrm{mg} / \mathrm{dl}$ caused a 30fold increase in atherosclerotic lesions. On the other hand, when most of the cholesterol is in the VLDL size range (as in the two groups of apo-E-deficient mice), increasing the plasma cholesterol levels from approximately 300 to approximately $450 \mathrm{mg} / \mathrm{dl}$ increased the extent of atherosclerotic lesions less than twofold.

Other observations are consistent with the view that lipoprotein size could have a significant effect on the plasma cholesterol versus atherosclerosis curve. More than 50 years ago, Duff and McMillan (34) reported that diabetic cholesterol-fed rabbits are less susceptible to atherosclerosis than are nondiabetic rabbits. The diabetic rabbits were hypercholesterolemic, but in addition were extremely hypertriglyceridemic (plasma triglyceride levels > 5,000 mg/dl). Several explanations for the resistance of the diabetic rabbits to atherosclerosis have been proposed, but the prevailing view holds that the large size of cholesterol-carrying lipoproteins prevented them from contributing to atherogenesis $(35,36)$. Most of the cholesterol in the diabetic rabbits is contained in giant lipoproteins (37) having diameters greater than $75 \mathrm{~nm}$, and several studies have suggested that fewer of these lipoproteins than of the smaller lipoproteins enter the arterial wall $(3,35,36)$. Several studies have shown that the permeability of VLDL into the arterial wall is lower than that of $\operatorname{LDL}(3,37-39)$.

In LDL receptor-deficient mice, replacing the two $A p o b^{+}$alleles with $A p o b^{100}$ alleles caused the plasma levels of cholesterol to increase by approximately 100 $\mathrm{mg} / \mathrm{dl}$ and atherosclerotic lesions to increase 30 -fold. Although this finding might at first seem extraordinary, it actually might be quite consistent with several findings in the literature. For example, on a high-fat diet, total plasma cholesterol levels in wild-type mice increase to approximately $240 \mathrm{mg} / \mathrm{dl}$, owing to an accumulation of VLDL-IDL cholesterol (40). Adding a human apo-B transgene has little if any effect on the VLDL-IDL accumulation but substantially increases LDL cholesterol, elevating the total cholesterol levels to approximately $320 \mathrm{mg} / \mathrm{dl}$. This rather modest increase in LDL ( 80 $\mathrm{mg} / \mathrm{dl}$ ) is associated with an 11-fold increase in the extent of atherosclerosis. Similarly, Powell-Braxton and coworkers (10) found that increasing the LDL levels in Apobec1 knockout mice resulted in a striking increase in atherosclerosis. A steep LDL-atherosclerosis curve is probably not simply a peculiarity of the mouse. In humans, where most of the plasma cholesterol is in the LDL fraction, a twofold increase in the plasma cholesterol levels (from 160 to $340 \mathrm{mg} / \mathrm{dl}$ ) is associated with a sixfold increase in coronary disease risk (41).

We recognize that factors other than lipoprotein size and number could have affected the severity of the atherosclerosis in Ldlr ${ }^{-1}$ Apob ${ }^{100 / 100}$ and Apoe-/-Apob $100 / 100$ mice. For example, the presence of apo-E in the VLDL and LDL of Ldlr/-Apob ${ }^{100 / 100}$ mice might increase the binding of those lipoproteins to proteoglycans within
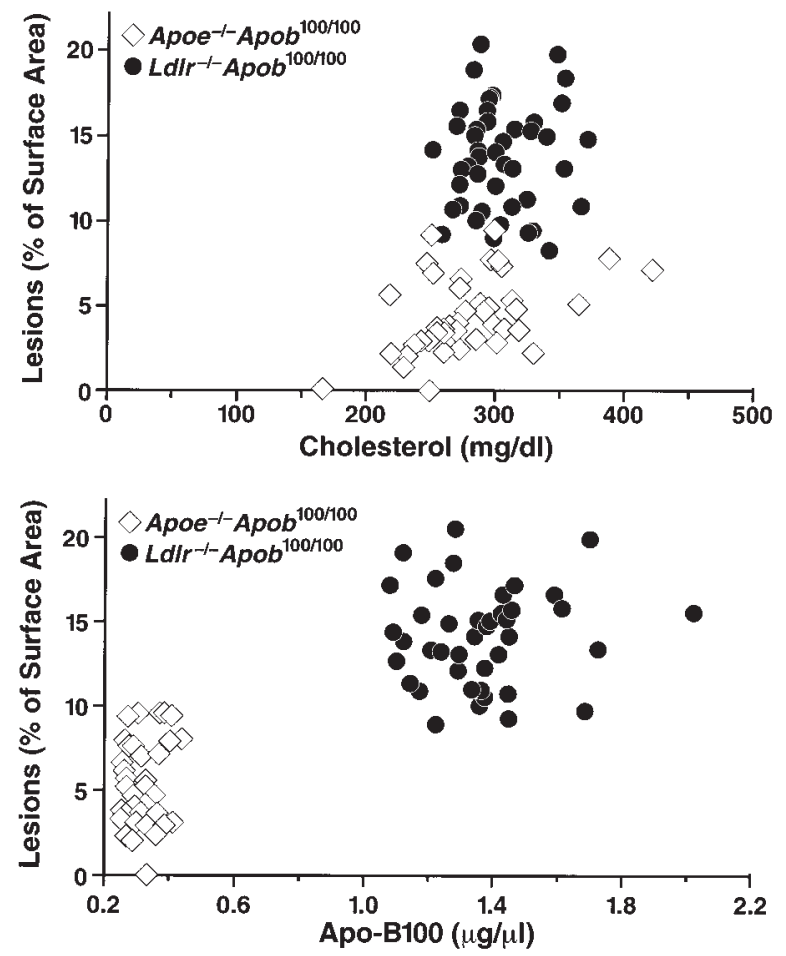

\section{Figure 7}

Relationship between atherosclerotic lesions and the total plasma cholesterol levels and plasma apo-B100 levels in Apoe ${ }^{-/-} A p o b^{100 / 100}(n=41)$ and $L d I r^{\prime-A p o b} b^{100 / 100}(n=40)$ mice. The top shows a plot lot of lesions, as assessed by morphometric techniques, versus total plasma cholesterol levels (mean of the five measurements). The bottom shows a plot of lesions versus the plasma apo-B100 levels (measured at 32 weeks). 
a

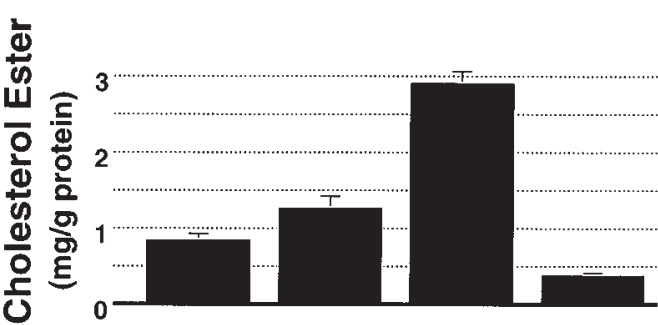

b

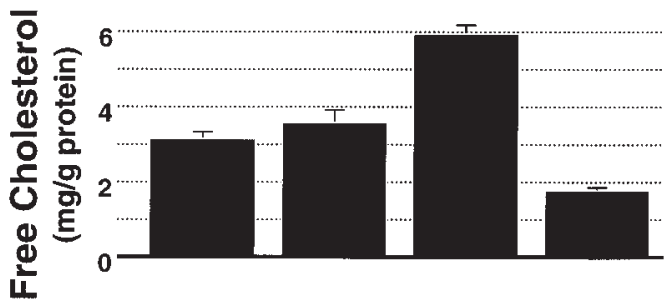

c

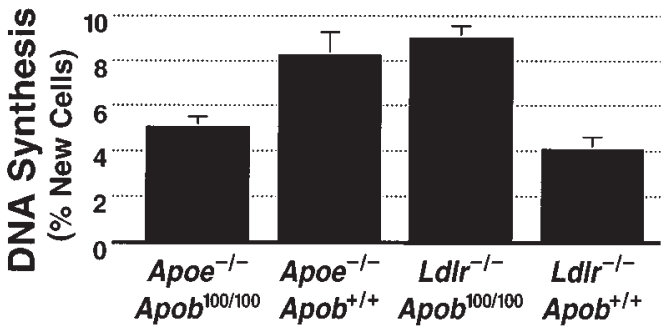

Figure 8

Scoring of aortic pathology in the four groups of mice according to the aortic content of free and esterified cholesterol and aortic DNA synthesis rate. (a) Cholesterol ester content of aortas in

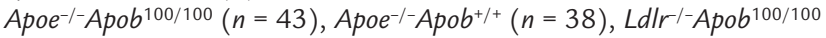
$(n=39)$, and $\mathrm{Ldll}^{-1-A p o b} \mathrm{~b}^{+/+}(n=34)$ mice. (b) Free cholesterol content of aortas in the four different groups of mice (numbers of mice are identical to those for a). (c) Aortic DNA synthesis rates in

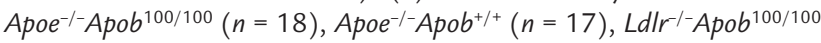
$(n=25)$, and $L d l r^{-/} A$ pob $^{+/+}(n=14)$ mice.

the arterial wall intima, increasing lipoprotein retention and accelerating atherogenesis. Similarly, the apo-AIand apo-AIV-enrichment of the VLDL and LDL from $A p o e^{-/-} A p o b^{100 / 100}$ could have had the opposite effect. It is also possible that LDL in the $\mathrm{Ldlr}^{-/}-A p o b^{100 / 100}$ mice might be more susceptible to oxidation (42), either because of differences in chemical composition or because of a longer half-life in the plasma (43).

We also considered the possible impact of apo-E production by arterial wall macrophages on the extent of atherosclerosis. In our studies, the macrophages in $L d l r^{-}-A p o b^{100 / 100}$ mice obviously retain the capacity to produce apo-E, whereas those in $A p o e^{-/-} A p o b^{100 / 100}$ mice do not. Several studies have suggested that the local production of apo-E within the arterial wall can limit the progression of lesions. For example, Fazio et al. (44) have shown that adoptive transfer of Apoe-/- bone marrow into wild-type mice increases lesion progression, whereas others have found that apo-E overexpression in macrophages reduces the extent of atherosclerosis (45). However, this anti-atherogenic role of apo-E in the arte- rial wall could not explain our results, as our mice that retained the ability to synthesize apo-E (e.g., $L d l r^{-}$Apob $b^{100 / 100}$ mice) had more atherosclerosis than did mice lacking this capacity (e.g., the two groups of apoE-deficient mice). Boisvert and Curtiss (46) found, however, that the adoptive transfer of $A p o e^{-/-}$bone marrow into wild-type mice reduced lesion progression. Thus, their study suggested that apo-E synthesis in the arterial wall might be pro-atherogenic - a conclusion opposite from the one reached by Fazio and coworkers. If arterial wall apo-E synthesis were proatherogenic, that could help to explain the severe atherosclerosis in $L d l r^{-}-A p o b^{100 / 100}$ mice. In a similar vein, one might reasonably question whether absent LDL receptor expression by macrophages of $L d l r^{-}-A p o b^{100 / 100}$ mice had an impact on our studies. However, bone marrow transplantation studies have indicated that LDL receptor expression by macrophages has little effect on lesion development in chow-fed mice (47).

Another factor to be considered is the fact that the plasma levels of triglycerides were higher in Apoe $^{-/}$Apob $b^{100 / 100}$ mice $(\sim 150 \mathrm{mg} / \mathrm{dl})$ than in $L d l{ }^{-} / A^{-}$pob ${ }^{100 / 100}$ mice $(\sim 90 \mathrm{mg} / \mathrm{dl})$. We doubt, however, that the higher plasma triglyceride levels in Apoe-/-Apob ${ }^{100 / 100}$ mice had a significant impact on the extent of atherosclerotic lesions, as we previously found no relationship between plasma triglyceride levels and atherosclerosis in apo-E-deficient mice (16). We also doubt that HDL cholesterol levels were important determinants in the outcome of our experiments. In numerous FPLC fractionation experiments, we never observed a difference in the height or shape of the HDL cholesterol peak in $A p o e^{-/} A p o b^{100 / 100}$ and $\mathrm{Ldll}^{-/} A p o b^{100 / 100}$ mice.

Each of the four groups of mice had a similar genetic background, $75 \%$ C57BL/6 and 25\% 129/SvJae, but

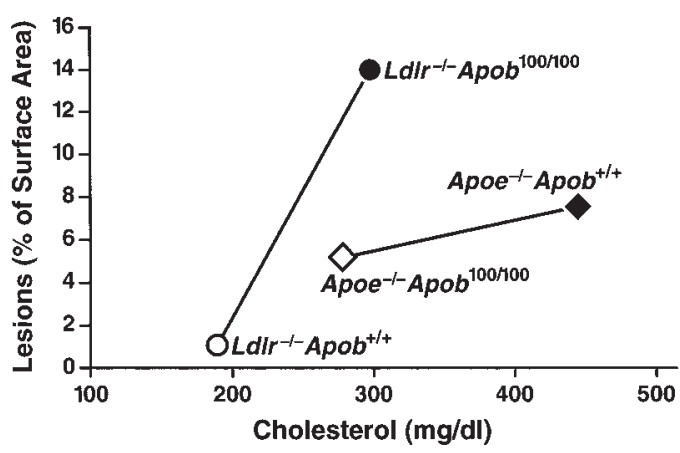

Figure 9

Mean extent of atherosclerotic lesions plotted against the mean total plasma cholesterol level. The atherosclerosis data (assessed by morphometric techniques) and the cholesterol data represent means calculated from all of the mice in each group. The steep increase in atherosclerosis in the LDL receptor-deficient mice between total cholesterol concentrations of $\sim 200$ and $300 \mathrm{mg} / \mathrm{dl}$ may be a consequence of the small apo-B-containing lipoproteins in those mice. However, this finding may in part reflect the lower HDL cholesterol levels in Ldl/ ${ }^{1-} A p o b^{100 / 100}$ mice than in $L d l r^{1-} A p o b^{+/+}$ mice (see Figure 1). 
they were not inbred. We considered the possibility that the mixed genetic background might have resulted in spurious findings, conceivably contributing to the striking differences in atherosclerosis in Ldlr- ${ }^{-}$Apo $b^{100 / 100}$ and Apoe ${ }^{-/} A p o b^{100 / 100}$ mice. However, we concluded that this was unlikely. First, we bred our study mice from multiple independent pairs of double gene-targeted mice and used very large group sizes strategies that should have reduced the chance of random genetic strain influences producing spurious findings. Second, we studied two control groups that were bred from littermates. Spurious genetic influences would most likely have appeared in one or both of the control groups. However, this did not occur: the extent of atherosclerosis in the control groups was in line with results expected from previously published studies (8, $12,13,48)$. Third, the severe atherosclerosis in $L d l r^{-}-A p o b^{100 / 100}$ mice was consistent with findings in other mice with high LDL levels, such as $\mathrm{HuBTg}^{+/+} \mathrm{Ldlr}^{-/}$mice (9) or Apobec1 $1^{-/-} \mathrm{Ldlr}^{--}$mice (10). Finally, it is noteworthy that Powell-Braxton recently quantified atherosclerotic lesions in inbred and outbred (C57BL/6) Ldlr-1-Apobec1-/- mice and found that the extent of atherosclerosis was quite similar (L. Powell-Braxton, personal communication).

An important aspect of the current study was the use of three independent methods to assess arterial pathology - morphometry, measurement of aortic free and esterified cholesterol content, and measurement of aortic DNA synthesis rates. We found a strong positive correlation between visible lesions and the content of free and esterified cholesterol in the aorta. Accordingly, we believe that it would be reasonable to substitute lipid measurements for morphometric approaches in many experiments, although this would probably not be appropriate in every situation (49).

New with the current study was the application of a technique for measuring DNA synthesis/cell proliferation in the mouse aorta. Stable isotope incorporation into DNA along with mass spectrometry makes it possible to measure DNA synthesis rates, and thus cell proliferation, with small amounts of genomic DNA, and to do so very accurately. The validity of this method is supported by the fact that the DNA synthesis rates and the biochemical/morphometric indices of atherosclerosis exhibited the same overall pattern (see Figures 4 and 8 ) in the different groups of mice. Equally interesting, however, were the relatively low (albeit highly statistically significant) correlation coefficients between the DNA synthesis measurement and the biochemical/morphometric indices. Given the extraordinary accuracy of mass spectrometry, we doubt that the relatively weak correlations can be attributed to errors in the DNA synthesis measurements. One possible explanation for the relatively weak correlations is that we assessed DNA synthesis in the entire aorta and thus may have contaminated our measurements with cell populations not directly involved in the atherogenic process. If so, better correlations would be expected in the setting of more advanced lesions. Another possibility is that genetic factors may have introduced variability into the relationship between lesion size and DNA synthesis. We believe that a great deal remains to be learned regarding cell proliferation in mouse atherogenesis. In the future, it will be important to measure DNA synthesis in mice with more extensive atherosclerotic lesions and in mice with different genetic backgrounds. We also believe it will be important to measure cell proliferation in different layers of the arterial wall (e.g., intima versus media). All of these issues are easily approachable with the stable isotope/mass spectrometry techniques described here.

\section{Acknowledgments}

We thank R.A. Neese for mass spectrometry of the aortic DNA samples; D. Sanan and D. Newland for advice on morphometric analyses; J. Rutledge for helpful discussions; L. Powell-Braxton for sharing unpublished data; and L. B. Nielsen, J. Bjorkegren, S. Ordway, and G. Howard for comments on the manuscript. This project was supported in part by NIH grants HL47660 (to S.G. Young), HL60844 (to R.L. Walzem), and HL49373 (to L.L. Rudel), a grant from the University of California Tobacco-related Disease Research Program (to S.G. Young), and Project 8738 of the Texas Agricultural Experiment Station (to R.L. Walzem).

1. Grundy, S.M. 1986. Cholesterol and coronary heart disease. A new era. JAMA. 256:2849-2858.

2. Krauss, R.M. 1998. Atherogenicity of triglyceride-rich lipoproteins. Am. J. Cardiol. 81:13B-17B.

3. Shaikh, M., et al. 1991. Quantitative studies of transfer in vivo of low density, Sf 12-60, and Sf 60-400 lipoproteins between plasma and arterial intima in humans. Arterioscler. Thromb. 11:569-577.

4. Goldstein, J.L., Hobbs, H.H., and Brown, M.S. 1995. Familial hypercholesterolemia. In The Metabolic and molecular bases of inherited disease. 7 th edition. Volume 2. C.R. Scriver, A.L. Beaudet, W.S. Sly, and D. Valle, editors. McGraw-Hill. New York, New York, USA. 1981-2030.

5. Mahley, R.W., and Rall, S.C., Jr. 1995. Type III hyperlipoproteinemia (dysbetalipoproteinemia): the role of apolipoprotein $\mathrm{E}$ in normal and abnormal lipoprotein metabolism. In The Metabolic and molecular bases of inherited disease. 7 th edition. C.R. Scriver, A.L. Beaudet, W.S. Sly, and D. Valle, editors. McGraw-Hill. New York, New York, USA. 1953-1980.

6. Krauss, R.M., et al. 1987. Intermediate-density lipoproteins and progression of coronary artery disease in hypercholesterolaemic men. Lancet. 2:62-66.

7. Piedrahita, J.A., et al. 1992. Generation of mice carrying a mutant apolipoprotein E gene inactivated by gene targeting in embryonic stem cells. Proc. Natl. Acad. Sci. USA. 89:4471-4475.

8. Zhang, S.H., Reddick, R.L., Piedrahita, J.A., and Maeda, N. 1992. Spontaneous hypercholesterolemia and arterial lesions in mice lacking apolipoprotein E. Science. 258:468-471.

9. Sanan, D.A., et al. 1998. Low density lipoprotein receptor-negative mice expressing apolipoprotein B-100 develop complex atherosclerotic lesions on a chow diet: no accentuation by apolipoprotein(a). Proc. Natl. Acad. Sci. USA. 95:4544-4549.

10. Powell-Braxton, L., et al. 1998. A mouse model of human familial hypercholesterolemia: markedly elevated low density lipoprotein cholesterol levels and severe atherosclerosis on a low-fat chow diet. Nat. Med. 4:934-938.

11. Reddick, R.L., Zhang, S.H., and Maeda, N. 1994. Atherosclerosis in mice lacking apo E. Evaluation of lesional development and progression. Arterioscler. Thromb. 14:141-147.

12. Plump, A.S., et al. 1992. Severe hypercholesterolemia and atherosclerosis in apolipoprotein E-deficient mice created by homologous recombination in ES cells. Cell. 71:343-353.

13. Nakashima, Y., et al. 1994. ApoE-deficient mice develop lesions of all phases of atherosclerosis throughout the arterial tree. Arterioscler. Thromb. 14:133-140.

14. Ishibashi, S., et al. 1993. Hypercholesterolemia in low density lipopro- 
tein receptor knockout mice and its reversal by adenovirus-mediated gene delivery. J. Clin. Invest. 92:883-893.

15. Ishibashi, S., et al. 1994. Massive xanthomatosis and atherosclerosis in cholesterol-fed low density lipoprotein receptor-negative mice. J. Clin. Invest. 93:1885-1893.

16. Véniant, M.M., et al. 1997. Susceptibility to atherosclerosis in mice expressing exclusively apolipoprotein B48 or apolipoprotein B100. J. Clin. Invest. 100:180-188.

17. Ishibashi, S., et al. 1994. The two-receptor model of lipoprotein clearance: tests of the hypothesis in "knockout" mice lacking the low density lipoprotein receptor, apolipoprotein E, or both proteins. Proc. Natl. Acad. Sci. USA. 91:4431-4435.

18. Farese, R.V., Jr., et al. 1996. Phenotypic analysis of mice expressing exclusively apolipoprotein B48 or apolipoprotein B100. Proc. Natl. Acad. Sci. USA. 93:6393-6398.

19. Véniant, M.M., et al. 1998. Lipoprotein clearance mechanisms in LDL receptor-deficient "apo-B48-only" and "apo-B100-only" mice. J. Clin. Invest. 102:1559-1568.

20. Linton, M.F., et al. 1993. Transgenic mice expressing high plasma concentrations of human apolipoprotein B100 and lipoprotein(a). J. Clin. Invest. 92:3029-3037.

21. Farese, R.V., Jr., et al. 1995. Knockout of the mouse apolipoprotein B gene results in embryonic lethality in homozygotes and protection against diet-induced hypercholesterolemia in heterozygotes. Proc. Natl. Acad. Sci. USA. 92:1774-1778.

22. Rudel, L.L., et al. 1998. Dietary monounsaturated fatty acids promote aortic atherosclerosis in LDL receptor-null, human apoB100-overexpressing transgenic mice. Arterioscler. Thromb. Vasc. Biol. 18:1818-1827.

23. Zlot, C.H., et al. 1999. Generation of monoclonal antibodies specific for mouse apolipoprotein B-100 in apolipoprotein B-48-only mice. J. Lipid Res. 40:76-84.

24. McCormick, S.P.A., et al. 1996. Transgenic mice that overexpress mouse apolipoprotein B. Evidence that the DNA sequences controlling intestinal expression of the apolipoprotein B gene are distant from the structural gene. J. Biol. Chem. 271:11963-11970.

25. Walzem, R.L., Davis, P.A., and Hansen, R.J. 1994. Overfeeding increases very low density lipoprotein diameter and causes the appearance of a unique lipoprotein particle in association with failed yolk deposition. $J$. Lipid Res. 35:1354-1366.

26. Tangirala, R.K., Rubin, E.M., and Palinski, W. 1995. Quantitation of atherosclerosis in murine models: correlation between lesions in the aortic origin and in the entire aorta, and differences in the extent of lesions between sexes in LDL receptor-deficient and apolipoprotein E-deficient mice. J. Lipid Res. 36:2320-2328.

27. Lowry, O.H., Rosebrough, N.J., Farr, A.L., and Randall, R.J. 1951. Protein measurement with the Folin phenol reagent. J. Biol. Chem. 193:265-275.

28. Macallan, D.C., et al. 1998. Measurement of cell proliferation by labeling of DNA with stable isotope-labeled glucose: studies in vitro, in animals, and in humans. Proc. Natl. Acad. Sci. USA. 95:708-713.

29. Hellerstein, M., et al. 1999. Directly measured kinetics of circulating T lymphocytes in normal and HIV-1-infected humans. Nat. Med. 5:83-89.

30. McCune, J.M., et al. 2000. Factors influencing T-cell turnover in HIV1-seropositive patients. J. Clin. Invest. 105:R1-R8.

31. Misell, L., et al. 2000. A new in vivo stable isotope method for measuring mammary epithelial cell proliferation. FASEB J. 14:A786. (Abstr.)

32. Antelo, F., Neese, R., and Hellerstein, M.K. 2000. Measuring adipocyte proliferation in vivo using ${ }^{2} \mathrm{H}_{2} \mathrm{O}$ incorporation into DNA. FASEB J. 14:A214. (Abstr.)

33. Schaefer, E.J., et al. 1986. Familial apolipoprotein E deficiency. J. Clin.
Invest. 78:1206-1219.

34. Duff, G.L., and McMillan, G.C. 1949. The effect of alloxan diabetes on experimental cholesterol atherosclerosis in the rabbit. I. The inhibition of experimental cholesterol atherosclerosis in alloxan diabetes. II. The effect of alloxan diabetes on the retrogression of experimental cholesterol atherosclerosis. J. Exp. Med. 89:611-630.

35. Nordestgaard, B.G., Stender, S., and Kjeldsen, K. 1988. Reduced atherogenesis in cholesterol-fed diabetic rabbits. Giant lipoproteins do not enter the arterial wall. Arteriosclerosis. 8:421-428.

36. Nordestgaard, B.G., and Zilversmit, D.B. 1988. Large lipoproteins are excluded from the arterial wall in diabetic cholesterol-fed rabbits. J. Lipid Res. 29:1491-1500.

37. Stender, S., and Zilversmit, D.B. 1981. Transfer of plasma lipoprotein components and of plasma proteins into aortas of cholesterol-fed rabbits. Molecular size as a determinant of plasma lipoprotein influx. Arteriosclerosis. 1:38-49.

38. Nordestgaard, B.G., Tybjaerg-Hansen, A., and Lewis, B. 1992. Influx in vivo of low density, intermediate density, and very low density lipoproteins into aortic intimas of genetically hyperlipidemic rabbits. Roles of plasma concentration, extent of aortic lesion, and lipoprotein particle size as determinants. Arterioscler. Thromb. 12:6-18.

39. Nordestgaard, B.G., Wootton, R., and Lewis, B. 1995. Selective retention of VLDL, IDL, and LDL in the arterial intima of genetically hyperlipidemic rabbits in vivo. Molecular size as a determinant of fractional loss from the intima-inner media. Arterioscler. Thromb. Vasc. Biol. 15:534-542.

40. Purcell-Huynh, D.A., et al. 1995. Transgenic mice expressing high levels of human apolipoprotein B develop severe atherosclerotic lesions in response to a high-fat diet. J. Clin. Invest. 95:2246-2257.

41. Neaton, J.D., and Wentworth, D. 1992. Serum cholesterol, blood pressure, cigarette smoking, and death from coronary heart disease. Overall findings and differences by age for 316,099 white men. Arch. Intern. Med. 152:56-64.

42. Witztum, J.L. 1994. The oxidation hypothesis of atherosclerosis. Lancet. 344:793-795

43. Walzem, R.L., et al. 1995. Older lipoproteins are more susceptible to oxidation: a linking mechanism for the lipid and oxidation theories of atherosclerotic cardiovascular disease. Proc. Natl. Acad. Sci. USA. 92:7460-7466.

44. Fazio, S., et al. 1997. Increased atherosclerosis in mice reconstituted with apolipoprotein E null macrophages. Proc. Natl. Acad. Sci. USA. 94:4647-4652.

45. Bellosta, S., et al. 1995. Macrophage-specific expression of human apolipoprotein $\mathrm{E}$ reduces atherosclerosis in hypercholesterolemic apolipoprotein E-null mice. J. Clin. Invest. 96:2170-2179.

46. Boisvert, W.A., and Curtiss, L.K. 1999. Elimination of macrophage-specific apolipoprotein E reduces diet-induced atherosclerosis in C57BL/6J male mice. J. Lipid Res. 40:806-813.

47. Linton, M.F., Babaev, V.R., Gleaves, L.A., and Fazio, S. 1999. A direct role for the macrophage low density lipoprotein receptor in atherosclerotic esion formation. J. Biol. Chem. 274:19204-19210.

48. Zhang, S.H., Reddick, R.L., Burkey, B., and Maeda, N. 1994. Diet-induced atherosclerosis in mice heterozygous and homozygous for apolipoprotein E gene disruption. J. Clin. Invest. 94:937-945.

49. Accad, M., et al. 2000. Massive xanthomatosis and altered composition of atherosclerotic lesions in hyperlipidemic mice lacking acyl CoA:choesterol acyltransferase 1. J. Clin. Invest. 105:711-719.

50. Véniant, M.M., et al. 1998. Lipoprotein clearance mechanisms in LDL receptor-deficient "apoB-48 only" and "apoB-100-only" mice. J. Clin. Invest. 102:1559-1568. 